\title{
Creating the Approach for the Evaluation Level of the Efficiency of the Organizational Culture of the Sea Port
}

\author{
Maryna Makarenko* \\ Department of Sea Transport \\ Management and Entrepreneurship \\ Azov Maritime Institute of the National \\ University "Odessa Marine Academy" \\ Mariupol, Ukraine \\ https://orcid.org/0000-0003-2006-3474
}

\author{
Roman Ustynov \\ Department of Sea Transport \\ Management and Entrepreneurships \\ Azov Maritime Institute of the National \\ University "Odessa Marine Academy" \\ Mariupol, Ukraine \\ https://orcid.org/0000-0003-4288-1072 \\ Olena Sienko \\ Department of Management and Sea \\ Transport Economics \\ National University "Odessa Marine \\ Academy" \\ Odessa, Ukraine \\ https://orcid.org/0000-0001-6651-9343
}

\author{
Marina Babachenko \\ Department of Management and Sea \\ Transport Economics \\ National University "Odessa Marine \\ Academy" \\ Odessa, Ukraine \\ https://orcid.org/0000-0002-4849-3946
}

\begin{abstract}
It has been proved that efficiency of the management of the modern enterprise of the marine industry is defined by the obtained level of its organizational culture, therefore, there is a necessity to deal with the issues of creating corresponding conditions for developing organizational culture. Components of enterprise organizational culture have been structured by determining two groups of functional and social culture and there have been defined corresponding integral elements of organizational culture which are given from the position of its forming in each functional sphere of the enterprise: production, marketing, management, personnel, economic culture, financial culture, quality of working life, social and psychological climate, motivation. This structural model gives an opportunity to investigate the character of organizational structure, patterns of its creation and development and to make a complex view concerning the enterprise organizational culture. It has been highlighted that management of the enterprise organizational culture has to ground on defining the state of each of the indicators mentioned above that characterize the components of the organizational culture. For defining that state there is a necessity to provide the assessment of the power of culture by particular indicators. Such indicative evaluation will suggest the enterprise authority the ways of targeted impact on the power of enterprise organizational culture. The procedure of indicative evaluation of such specific notion as the enterprise organizational culture has a number of particular features connected with the qualitative character of indicators as well as dependence of evaluations from the subjective view of a person providing it. There have to be thorough research to avoid these kinds of contradictions when providing the evaluation and to obtain the complex view concerning the power of the enterprise organizational culture. There have been substantiated the necessity of developing the tools for evaluating the level of the enterprise organizational culture which would assist in determining its components that require priority managerial influence. The approach to the evaluation of the efficiency level of the enterprise organizational culture has been developed which is grounded on the sequential synthesis of expert evaluations of the indicators that characterize determined components of organizational culture by various levels of
\end{abstract}

management. Each element of culture has been detailed which provides the management with the opportunity to direct remedial measures in the required manner. It has been recommended to present the obvious state of each component of organizational culture in geometric space. The method of evaluation the level of organizational culture efficiency has been tested in the state enterprise sea commercial port "Yuzhny". The application of such an approach allows determining the contribution of each component of the organizational culture into the overall efficiency and providing targeted adjustment in accordance with the goals of the enterprise. The building of the area of the figure has been suggested for each component of organizational culture which facilitates its increase.

Keywords-innovative activity, human resources, rating estimation, seaports, human resources management

\section{INTRODUCTION}

Sea transport has a great importance for the development of the economy of any state as it provides sea international relations of the country and supports stable transport routes with other world regions. Yet, the increasing competition from the foreign ports, globalization of the economy that deepens world specialization and integration of the production greatly influence the activity of the ports and demand finding new modern tools of management which would provide high competitiveness of sea industry enterprises. One of these components is enterprise organizational culture that allows raising the position of the enterprise at the market and contributes to the strategic flexibility and provides ongoing transformation.

The efficiency of the modern sea industry enterprise management is determined by the obtained level of its organizational culture, therefore, it is necessary to deal with the issues of creating the corresponding conditions for shaping the organizational culture. 


\section{STRUCTURAL MODEL OF THE ENTERPRISE ORGANIZATIONAL CULTURE}

The enterprise culture can shape in different functional subsystems of the enterprise: production, marketing, management, labor organization, work with the personnel, finances and economy, etc.

As each enterprise is unique, the identical elements of the enterprise organizational culture structure can behave differently and have different importance for the enterprise. Thus, the peculiarities of each of them are determined not by the various connections of shapes and elements as they are all characteristic for any enterprise but by the intensity of manifestation of these elements. Integral influence of all elements that depicts the level of the culture in this or that sphere shapes the type of enterprise culture which possesses certain features.

Consequently, the ground for the complex research of the enterprise culture is the shaping of the structural model and research of its structural elements and further consideration of different variants of their interaction.

Determining the elements of the enterprise culture that makes its structure is a hard task.

Taking into consideration the above mentioned approaches we can say that two approaches can be implemented. One of them is based on the research of culture essence where the structural elements include ethics, philosophy, traditions, rituals and values. The second approach deals with establishing functional spheres of the enterprise each of them having its own culture.

Moreover, it should be underlined that in our opinion all elements of the enterprise culture structure can be divided into two groups: functional culture and social culture.

The purpose of the functional culture lies in creating and supporting the system of sanctioned behavioral acts that facilitate the shaping of behavior pattern directed to reaching the strategic goals of the enterprise. It is constructed from "above" by the management. It is characterized by creating and supporting the system of sanctioned behavioral relations that facilitate shaping the behavioral pattern directed to reaching market or regular attractor by the enterprise, targeted activity caused by the competitiveness of the enterprise in the external environment, regulation of relations when the employees perform their labor functions.

Social culture mostly presents regular culture that is formed as a result of interrelation of group and individual subcultures. As a rule, it appears as a result of an evolutionary process which occurs both from "above" and "under", as the personnel as well as the management of the enterprise are interested in creating the unified reference system not only when performing their professional functions but also within the infrastructure and production processes. It is worth mentioning that the dominant subject of shaping social culture is personnel because it is them who due to their peculiar state are interested in creating and supporting social relations which assist in decreasing the level of insecurity and transaction loss in the process of group interaction. To provide the efficiency of the enterprise development, these elements should be of consistent character. In the process of enterprise development both culture of each cultural element and surface and subsurface levels of culture are formed. The underlying level of the culture remains constant. It is a base for all the enterprise and is born in the consciousness of the higher management. Thus, cultural development starts from inside. We should name the elements of the enterprise culture structure that are defined by their shaping in each functional sphere of the enterprise: production, marketing, management, personnel, economic culture, financial culture, culture of labor life quality, culture of social and psychological climate, motivational culture. It goes without saying that not all these elements if the structure influence the power of culture in the same manner. The elements of culture are unequal "Figure 1".

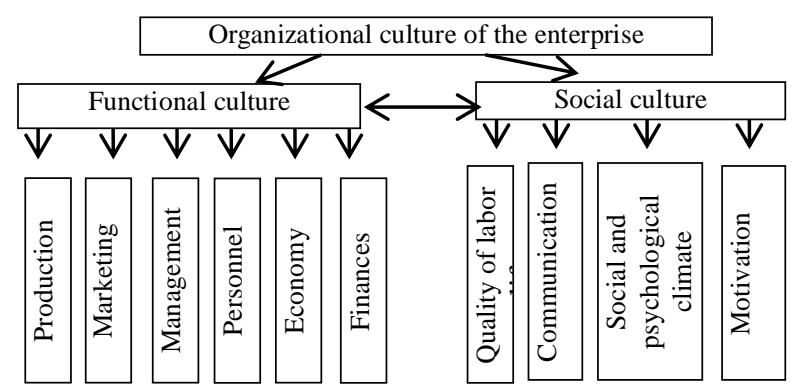

Fig. 1. Structural model of the enterprise organizational culture (complied by the author)

To define the level of manifestation of this or that structural element of the enterprise culture, the set of indicators should be named first. Determining the state of these indicators will assist in defining the level of the culture.

\section{GOALS AND TASKS FOR EVALUATION THE EFFICIENCY LEVEL OF THE ENTERPRISE ORGANIZATIONAL CULTURE}

The current period of the economical development is characterized by the change of the management paradigm, change of views on the enterprise organizational culture. More frequently human resources are considered by the enterprise management as a required condition for its economic growth. The results of most research have shown that the most frequently mentioned reasons for failures when applying reengineering, strategic management, controlling and other methods and tools of efficient management was negligence of organizational culture. In other words, the failure in the change of the organizational culture dominated over other initiated organizational changes. Until now not all national management authorities and representatives of human resources department have a clear understanding of the organizational culture. In the opinion of J. Kotter and J. Heskett [1] well-developed enterprise organizational culture reinforces coordination, control and unity of the enterprise goals with the employees' goals showing the priority importance of adaptation and necessity to adjust the internal environment of the company with its external environment. Scientists S. Shekshnya and M. Kets de Vries and others [2] are convinced that organizational culture is a key element of success in business. Thus, everything mentioned above leads to the necessity of continuing attempts for improving the management of the enterprise organizational culture. As the conducted research has shown determining the power of enterprise culture depends on a lot of elements. It is 
impossible to conduct the changes in the enterprise culture without a required preparation, randomly as they will result in nothing. Yet, matching the adequacy of enterprise organizational culture with the requirements of the external environment, goals and demands of the enterprise requires evaluation tools for the enterprise organizational culture, so for these purposes, there should exist well-established methodology. Thus, for making valid decisions regarding improvement or changes in enterprise organizational culture we need a tool which will assist in determining its elements that require priority managerial influence. Efficiency evaluation of the enterprise organizational culture presents this very tool. The subject of the evaluation must be the enterprise culture in general and its separate integral elements. The goal of conducting efficiency evaluation of the enterprise organizational culture is increase in competitiveness and enterprise efficiency due to determining the level of development of enterprise organizational culture and its separate elements. Each element of culture has its specific contribution and different meaning for the general result of the development of enterprise organizational culture. As the enterprise culture is a powerful tool of management, its thorough investigation and evaluation will allow determining enterprise competitive advantages. Consequently, it is possible to state the main goals and tasks for evaluation of power of enterprise organizational culture. "Figure 2"

\begin{tabular}{|c|c|}
\hline \multicolumn{2}{|c|}{$\begin{array}{l}\text { Evaluation of the efficiency level of the organizational culture of the } \\
\text { marine industry enterprise }\end{array}$} \\
\hline $\begin{array}{l}\text { Goals : } \\
\text { - capability for adaptation to } \\
\text { constantly changing conditions } \\
\text { of the exterior environment, } \\
\text { - capability of integration its } \\
\text { elements in an integral unity, } \\
\text { - being recognized by people } \\
\text { and other organizations } \\
\text { - correspond with the selected } \\
\text { strategy of the enterprise }\end{array}$ & $\begin{array}{l}\text { Tasks: } \\
\text { - determination of the state of the } \\
\text { enterprise organizational culture } \\
\text { elements, } \\
\text { - determination of the overall } \\
\text { efficiency of the enterprise } \\
\text { organizational culture, } \\
\text { - defining the main directions for } \\
\text { changes in the elements of the } \\
\text { enterprise organizational culture, } \\
\text { - selection of the actions } \\
\text { concerning the adaptation of the } \\
\text { enterprise culture to the changes in } \\
\text { the exterior environment and the } \\
\text { strategy of the enterprise }\end{array}$ \\
\hline
\end{tabular}

Fig. 2. Goals and tasks for evaluation of the efficiency level of the enterprise organizational culture

At present there have been developed a lot of approaches for evaluating the power of culture in foreign practice: K.Cameron, R. Quinna [3], T. Peters, R. Waterman [4], K. Davis [5], R. Quinn and J. Rohrbaugh [6], V.Sathe, T. Parsons [7], [8], I. Adizes, S. Robbins [9]. Yet this evaluation as well as evaluation suggested by national scientists do not possesses a complex character and do not cover all spheres of enterprise functions concentrating frequently on the manners of culture manifestation and not taking into consideration the reasons of their appearance.

\section{AlGORITHM OF CONSEQUENCE FOR CONDUCTING EFFICIENCY EVALUATION OF THE ENTERPRISE ORGANIZATIONAL CULTURE}

Efficiency evaluation of the enterprise organizational culture is conducted and analyzed in accordance with the corresponding elements of its structure by a number of indicators that characterize each of these elements. Efficiency evaluation of the enterprise organizational culture can be conducted with the help of qualitative parameters as in case when it is impossible to measure an indicator by using certain units of measure, i.e. those that have qualitative character, there appears a necessity to choose indicators which also possess qualitative character. All structural elements and indicators which characterize it apply to this case. In the first part, as a result of the survey of sea industry enterprises, the indicators for efficiency evaluation of enterprise organizational culture have been defined. The indicators were chosen through processing source literature and methods developed by the authors. Criterion for selection of the indicators characterizing the integral elements of the enterprise organizational culture was the scope of coverage and comprehensiveness. Thus, it is hard to evaluate indicators applying formalized approaches that is why methods of expert evaluation is used for their calculation. This method is described well and thoroughly if source literature [10], [11]. The surveyed expert groups were defined by the peculiarities of the studied phenomenon. As the enterprise culture should have consistency at different structural levels of management and at the level of regular employees and cover all functional spheres of the enterprise activity, a great number of personnel representatives was involved in the survey. All of them together made five expert groups and the data concerning them is given in "Tabl 1".

\section{TABLE I. GROUP OF EXPERTS ON EFFICIENCY EVALUATION OF THE} ENTERPRISE CULTURE

\begin{tabular}{|c|c|}
\hline Expert groups & $\begin{array}{c}\text { A number of } \\
\text { experts, persons }\end{array}$ \\
\hline Higher level of management & 5 \\
\hline Heads of middle level of management & 15 \\
\hline Heads of low level of management & 15 \\
\hline Professionals & 15 \\
\hline Personnel of technical departments & 15 \\
\hline Total number of experts & 65 \\
\hline
\end{tabular}

Thus, the algorithm of consequence for conducting efficiency evaluation of the enterprise organizational culture has the following features: the evaluation of the established indicators of the culture elements has a qualitative character; in the process of evaluation the expert survey is used and as a result the given evaluation is characterized by the subjective views of the persons who conduct it.

There are some difficulties when applying the qualitative evaluation of the efficiency of the enterprise organizational culture. It goes about the necessity of determining corresponding criteria which would allow to explain whether the obtained indicator shows high or low level of culture [12]. The expert group conducting the evaluation should have consensus concerning the identification of the obtained results. When the criteria of the evaluation do not exist, the group cannot direct their activity in the appropriate way. In case the representatives of the group keep different conceptions of result evaluation, they would probably fail to perform any evaluation at all [13]. The discussed criteria will allow defining the strong or weak points of the enterprise organizational culture. These variants of possible 
state of indicators that characterize the elements of enterprise organizational culture will allow finding out at which level it is present. For determining the efficiency of the enterprise organizational culture the experts are suggested filling in special tables by evaluating the state of each indicator. The tables of evaluation of the elements of the enterprise organizational culture developed for the experts show the results of the subjective views on the state of the enterprise organizational culture [14], [15] "Tabl 2".

TABLE II. EXPERT EVALUATION OF THE STRUCTURAL ELEMENTS OF THE ENTERPRISE CULTURE (AN EXTRACT)

\begin{tabular}{|c|c|c|c|c|c|c|}
\hline & \multirow{2}{*}{$\begin{array}{l}\text { The element of culture: } \\
\text { 1. Management culture: }\end{array}$} & \multicolumn{5}{|c|}{$\begin{array}{c}\text { The state of the indicator } \\
\text { (level of culture) }\end{array}$} \\
\hline & & 1 & 2 & 3 & 4 & 5 \\
\hline \multirow{9}{*}{ 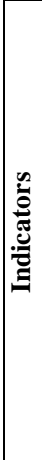 } & - style of management; & $\mathrm{x}$ & & & & \\
\hline & - level of the power centralization; & $\mathrm{x}$ & & & & \\
\hline & $\begin{array}{l}\text { - the level of the motivation system } \\
\text { efficiency; }\end{array}$ & & $\mathrm{x}$ & & & \\
\hline & $\begin{array}{l}\text { - professional training of the } \\
\text { management heads; }\end{array}$ & $\mathrm{x}$ & & & & \\
\hline & - career growth system; & & & $\mathrm{x}$ & & \\
\hline & $\begin{array}{l}\text { - the system of succession in the } \\
\text { management style; }\end{array}$ & & & & $\mathrm{x}$ & \\
\hline & $\begin{array}{l}\text { - the level of the management } \\
\text { competency; }\end{array}$ & & & & $\mathrm{x}$ & \\
\hline & $\begin{array}{l}\text { - the level of involving employees } \\
\text { into decision making process; }\end{array}$ & & & & & $\mathrm{x}$ \\
\hline & - the image of the leader & & & & & $\mathrm{x}$ \\
\hline & $\begin{array}{l}\text { The quantity of the corresponding } \\
\text { indicators }\end{array}$ & 4 & & & & 2 \\
\hline
\end{tabular}

We will underline one more peculiarity of the expert evaluation: the investigated indicator of the element of the enterprise organizational culture can appear at different levels and give a condition characteristic for the given element of culture efficiency. The task for the management in this case is in the first place to pay attention to those indicators that have the lowest evaluation in the generally low evaluation of the culture element. Thus, the objective view of the expert evaluation supposes generalization of the obtained results [11]. Such generalization is to be made for generalizing the evaluation of the indicators of each element in each expert group. At the next stage of the generalization the evaluations of the expert groups concerning the efficiency of the indicator of the corresponding structural element are put together. At the last stage of generalization the evaluations of different subgroups are put together and in this manner we obtain the evaluation of the efficiency of the corresponding structural element of the enterprise organizational culture. The results of efficiency evaluation of the enterprise organizational culture can be presented in the shape of a triangle built by the number of structural elements of the enterprise organizational culture. Each indicator has five sectors of evaluation from 0 to 5 "Tabl 3 " in practice the width of sectors for each structural element will correspond the coefficient of importance of these elements in the enterprise culture. Depending on the acquired coefficient of importance we determine the width of the area in the rectangle of evaluation. It is also determined with the assistance from the experts.

The state of each element of the enterprise organizational culture can be illustrated in the geometric space where the width of the element area depends on its importance for the enterprise organizational culture. The state of the enterprise organizational culture will be finally defined by the area of the rectangular shape.

It is obvious that the less the value of the area of the found geometric shape is, the better is the state of the element of the enterprise organizational culture. The mathematical area of the rectangle is what an integral element of the culture should reach in the process of its development.

The received calculations for each element of the culture give an opportunity to compare their total areas with the desired area of an ideal rectangle.

TABLE III. RESULTS OF THE EXPERT SURVEY WITH DETERMINING THE COEFFICIENTS OF IMPORTANCE OF STRUCTURAL ELEMENTS OF THE ENTERPRISE ORGANIZATIONAL STRUCTURE

\begin{tabular}{|c|c|c|c|c|c|c|c|c|c|c|}
\hline & \multicolumn{10}{|c|}{ Coefficients of importance of the spheres of evaluation } \\
\hline 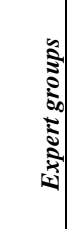 & 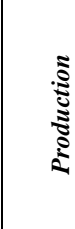 & 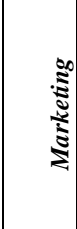 & 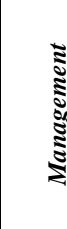 & 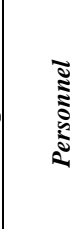 & $\begin{array}{r}\vec{\vdots} \\
\vdots \\
\vdots \\
0 \\
0\end{array}$ & 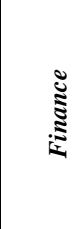 & 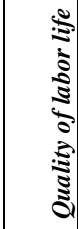 & 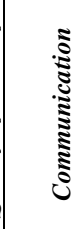 & 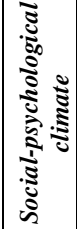 & 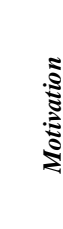 \\
\hline 1 & 0,150 & 0,040 & 0,120 & 0,190 & 0,080 & 0,04 & 0,060 & 0,085 & 0,095 & 0,14 \\
\hline 2 & 0,085 & 0,060 & 0,136 & 0,157 & 0,075 & 0,07 & 0,047 & 0,045 & 0,075 & 0,25 \\
\hline 3 & 0,075 & 0,050 & 0,120 & 0,145 & 0,030 & 0,03 & 0,060 & 0,025 & 0,065 & 0,40 \\
\hline 4 & 0,050 & 0,045 & 0,125 & 0,100 & 0,025 & 0,03 & 0,045 & 0,055 & 0,065 & 0,49 \\
\hline 5 & 0,065 & 0,060 & 0,130 & 0,150 & 0,045 & 0,05 & 0,060 & 0,065 & 0,035 & 0,35 \\
\hline $\begin{array}{l}\text { Ave- } \\
\text { rage }\end{array}$ & 0,085 & 0,051 & 0,126 & 0,148 & 0,051 & 0,05 & 0,054 & 0,055 & 0,067 & 0,33 \\
\hline
\end{tabular}

Thus, to make final conclusions and to provide practical recommendations concerning further development of the enterprise organizational culture it is necessary to present the interpretation of the possible values of the efficiency level of the enterprise organizational culture: high, middle, satisfactory, unsatisfactory "Tabl 4".

TABLE IV. VARIATIONS OF POSSIBLE EVALUATIONS OF THE EFFICIENCY LEVEL OF THE ENTERPRISE ORGANIZATIONAL CULTURE

\begin{tabular}{|c|c|}
\hline Area difference, $\%$ & $\begin{array}{c}\text { Efficiency level of the enterprise } \\
\text { organizational culture }\end{array}$ \\
\hline $0-25$ & high \\
\hline $25,1-50$ & middle \\
\hline $50,1-75$ & satisfactory \\
\hline $75,1-100$ & unsatisfactory \\
\hline
\end{tabular}

The obtained graphic representation in the form the geometric rectangular shape of the value of the structural elements of the enterprise organizational culture is considered to be a useful tool for making management decisions. The head may find the correspondence of this or that element and take measures as for improving or changing the situation.

\section{PRACTICAL APPROBATION OF THE SUGGESTED}

\section{APPROACH TO THE EVALUATION OF THE PORT CULTURE}

We will present the algorithm of consequence for conducting the efficiency evaluation of the enterprise organizational culture "Figure 3".

The group of experts from the employees of the biggest sea commercial port "Yuzhny" in Ukraine has conducted the evaluation of all elements of organizational culture. Generalization of the first stage is presented by such 
elements as management culture and culture of the labor life quality. Analysis of the results of evaluation of the element of labor life quality brings the conclusion that it is different for each professional group. Thus, the element being studied is the highest among the heads of the higher level and the lowest evaluation is received from the employees of the technical departments. Further, we have considered the extracts of the second state of the analysis of the elements of organizational culture of the state enterprise sea commercial port "Yuzhny".

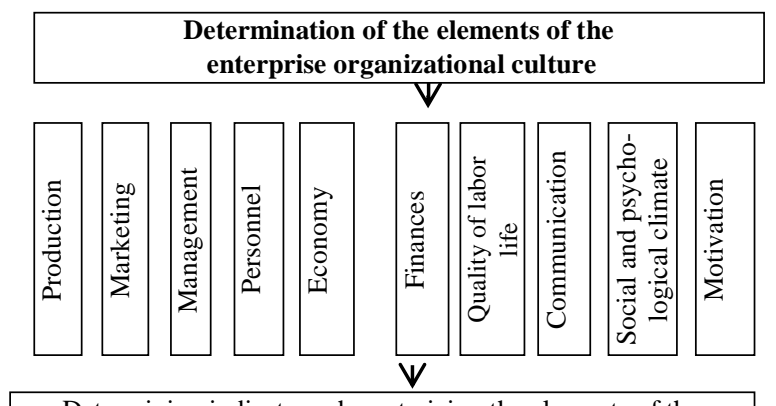

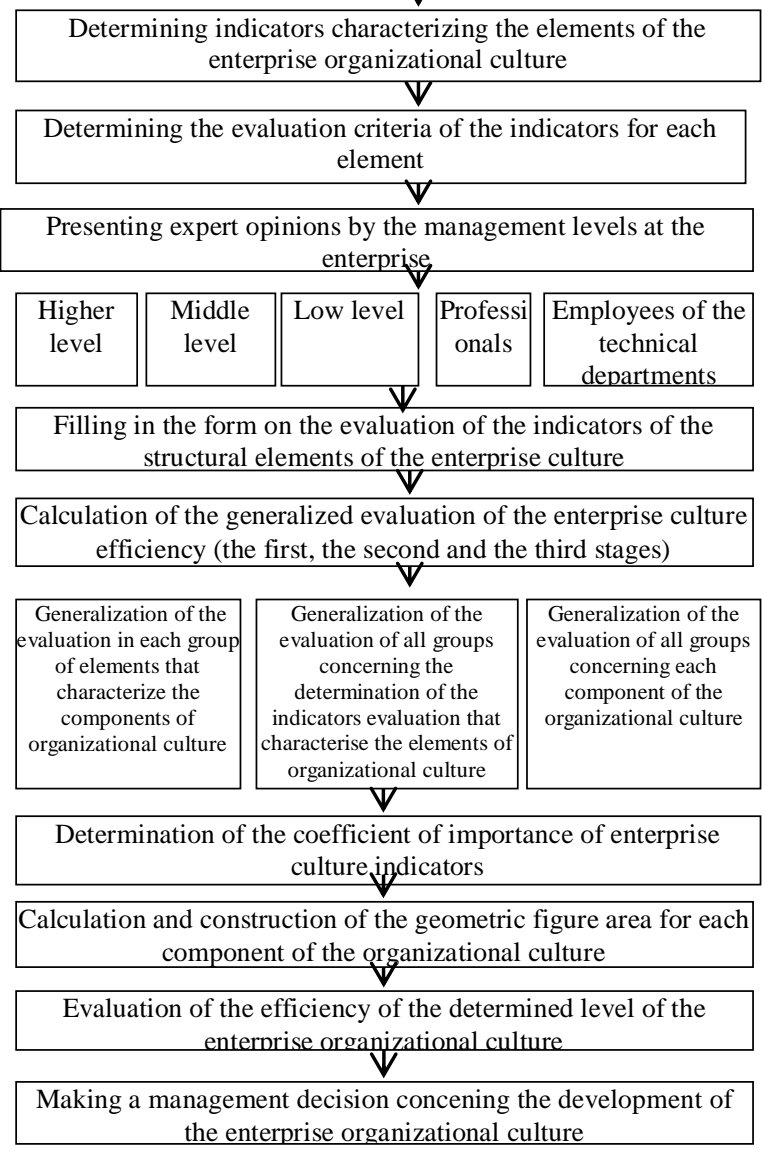

Fig. 3. The approach to the efficiency evaluation of the enterprise organizational culture (developed by the author)

Data presented on the diagram allows saying that the indicators characterizing the innovative component of the element "Production" are marked by low evaluation points.

Analysis of the next element has discovered the insufficient use of the advertising in the port activity and brand communication.

These elements should be paid attention to as they have a great importance for involving customers and raising the value of non-material assets of the port.

When evaluating the indicators of the element "Economy" we see rather low values of such indicators as "The presence of business planning system" and "Conducting management based on indicators" Application of these indicators in the management and modern business planning systems are becoming especially important in the current conditions of activity when the exterior environment of the enterprise is changing rapidly and the competition struggle for the customers and their cargo is growing..

The component of communication finds itself at a rather low position except the indicator "Provision of communication means". All other components should be increased.

The evaluation of the indicators presents to our attention a high level of personnel consolidation although the similarity of moral values is insufficiently high.

The results of the evaluation of the motivation component can be considered as high. It is well developed in marine industry.

General evaluation of the efficiency of the port culture is presented at "Figure 4".

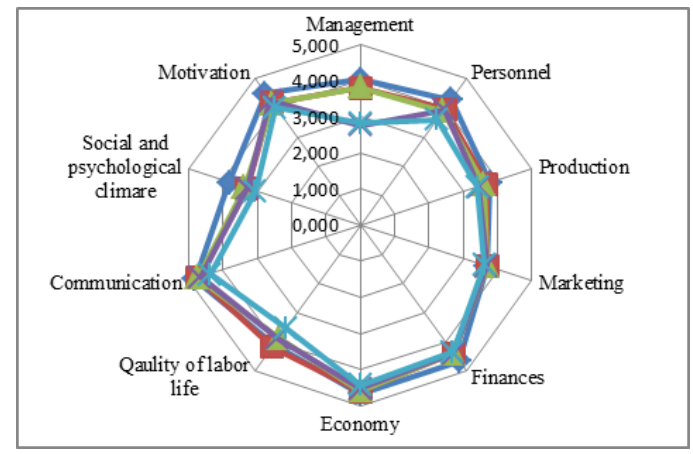

Fig. 4. Results of the general evaluation of the efficiency of the culture at sea commercial port Yuzhny

The data of this diagram show the evaluation results of the final stage where the results obtained from all expert groups are generated. Such presentation of the information allows seeing the result with highlighting of particular elements and their components and the management of the enterprise clearly sees the "narrow" places in the enterprise culture. It should be remembered that innovations are one of the main elements of the enterprise development.

Indicators presented on "Fig.4" show the high level of the personnel professional training. Attention should be paid to the low level of evaluation of such indicators as "Creativity and creative thinking" as well as "Correspondence of the personnel structure to the goals of the enterprise".

\section{CONCLUSIONS}

The obtained data classify the port as the enterprise with unsatisfactory state of the efficiency of the organizational culture. Thus, the application of the suggested evaluation tool allows us to get to the study of such a complex phenomenon as enterprise culture systematically with the application of the element analysis and experts methods. 
The enterprise being studied requires immediate implementation of measures concerning development of its organizational culture as it is currently at a very low level. Detailing of every culture element provides the management with an opportunity to direct corrective actions in the right manner.

Thus, the article has structured the components of the enterprise organizational culture by determining two groups of functional and social culture and has defined the corresponding integral elements of the organizational culture from the point of its forming in each functional sphere of the enterprise: production, marketing, management, personnel, economical culture, financial culture, quality of labor life, social and psychological climate, motivation. This structural model allows investigating the nature of the organizational structure, rules of its appearance and development and allows creating an overall view concerning the enterprise organizational culture.

The approach to the evaluation of the efficiency level of the enterprise organizational culture has been developed. It is based on the gradual generalization of the expert evaluations of the indicators that characterize the determined elements of organizational culture and them themselves by different management levels. The implementation of this approach allows determining the contribution of each element of the organizational culture in its general efficiency and performing targeted correction in accordance with the goals of the enterprise. The construction of the figure area for each component facilitating the growth of the organizational culture is suggested.

\section{REFERENCES}

[1] J. P., Kotter, J. L. Heskett, Corporate culture and performance, N. Y. Free press, 1992
[2] Kets de Vries M, S. Shekshnya, K. Krotov, E. Florent-Tracy. "New leaders of Russian business", M.: Alpina Business Bucs, 2001. [in Russian].

[3] K.Cameron, R.Quinn "Diagnosis and change in organizational culture", St. Petersburg: Peter, 2005. [in Russian].

[4] T.Peters, R.Waterman "In search of control efficiency, M.: Progress, 1998. [in Russian].

[5] K.Davis, "Can Business Afford To Ignore Social Responsibilities?" California Management Review, Vol. 2, no. 3. pp. 70-76, 1960.

[6] Robert E. Quinn, John Rohrbaugh, “Aspacial model of effectiveness criteria: Towards a competing values approach to organizational analysis, Management Science, pp. 363- 377, 1983.

[7] V.Sathe, Culture and Realated Corporate Réalités, Richard D. Irvin, Inc., 1985.

[8] V.Sathe, "Implications of corporate culture: A manager's guide to action. Organisational Dynamics", 12:4-23, 1983.

[9] I.Adizes, "Corporate Life Cycle Management", St. Petersburg.: Peter, 2007. [in Russian].

[10] S.A. Aivazian, V.S.Mkhitaryan, "Applied statistics. Basics of econometrics: in 2 vols. Probability theory and applied statistics", M.: UNITI-DANA, 2001. [in Russian].

[11] W.Kaufmann, Fuzzy mathematical models in engineering and management science, Amsterdam; New York: Elsevier Science Pub. Co, 1988 .

[12] O.Bieliakova, V.Onishchenko, R.Ustynov "Management of innovative behaviour of human resources", International Journal of Engineering@Technology,Vol.7., 2018.

[13] D.Solokha, L.Sotnichenko, S.Bessonova, A.Kravchenko, M.Makarenko, "Justification of business entities development based on innovative principles", Academy of Strategic Management Journa, Vol. 17. pp. 91-116, 2018.

[14] D.Solokha, S.Bessonova, M.Makarenko). "Features of Business Administration at different stages of Enterprise Life Cycle", International Journal of Engineering @ Technology,Vol.7, 2018.

L.Sotnichenko, A.Zaderey, "Formation of the Mechanism for Managing the Organizational Culture of the Marine Industry Enterprise“, Scientific Journal «Manager. Bulletin of Donetsk State University of Management, Series «Economics», Vol. 4 (81). pp.23-31. 2018. 